\title{
Honoring the Unseen
}

\section{Catherine Cabeen, Marymount Manhattan College}

Keywords: unseen, practice, cultural conditioning, transformation, somatic, embodiment, advocacy, social justice

The irony of writing to bring visibility to that which is intentionally unseen is not lost on me. Nonetheless, I feel that in response to a call for writing on "Where We Dance Now," it is important to acknowledge the value of aloneness; the value of dance practices not caught on camera, not uploaded to social media sites, not used to show who you are to others, but perhaps used to show who you are to yourself. What does it mean to dance in isolation? What is the value of dance that is not performative? Does dance matter when no one is watching? This provocation suggests that it does; because with or without an audience, dancing changes the dancer.

Before Covid, my private dance practices were in service of future live performances. However, as one performance opportunity after another was canceled in the spring, summer, and then the remainder of 2020, the process itself came under scrutiny. Without the enticement of a performance product to validate my practice within a capitalist society, I found myself asking —Why am I doing this? What/who is it for?

A quiet voice within kept calling out to, 'keep moving,' to celebrate the power of change and transformation that exists within each of our kinetic bodies. It was as if my cells were asking for the stimulation of momentum; a gateway to feeling alive, a counter-sensation to the trauma of the quarantined moment.

One of my greatest loves as a dancer in group choreography has been the opportunity to feel myself as part of a greater whole. The live, antiracist choreographies of protest, which emerged within the pandemic underscore (to use Nancy Stark Smith's term) during the summer of 2020, amplified my awareness that our physical bodies are always part of a greater whole. Our corporeality is constantly co-creating the social body. Dance practices, seen or unseen, create rich sites through which to interrogate our own role in culture and community. Within this work, unconscious bias is being increasingly recognized as an embodied phenomenon. Individually and collectively, we are being called to engage in deep practices of unpacking our habitual and culturally conditioned 
perspectives. This work, which allows us to show up to our communities whole and responsive, is essential, somatic, and often unseen.

Skin, cool against a wooden floor, dropping into that labyrinthine reflex, sensing my weight as it rides gravity towards the earth. The impulse to move, to shift, to pour my trillions of cells into a new form. It is a quiet call that guides me at first. Breath animates my body, calling up a dance of exchange with the space around me. Each inhale is an opportunity for nourishment and with each exhale I co-create the environment I inhabit. The form of my body and the shape of space around me play with fullness, emptiness, and possibility.

Tuning into breath I feel the privileges, struggles, joys, and fears that mark my particular body. I feel the limitations of perspective and the depth of responsibility held in each muscle fiber. Compassion emerges for myself and others with the core realization embodiment offers; that we are all operating from specific positionality.

Feeling my breath, I hear Black Lives Matter protesters, "I can't breathe." I stay with the discomfort; working through the suffocation of generational trauma, reclaiming breath as power, each exhale connecting to my voice. A yearning in my body spills into sound. I let it roll me through space, bringing me to my feet, which take over the song with a rhythmic shuffling.

The beat rides up my body from my feet into my pelvis and chest. Organs in my core move thickly around each other's density; unconscious digestion, integrating with rhythmic movement choices.

Dancing envelops my consciousness, detaching it from cyclical thinking in order to navigate shifts of weight and interconnectivity. Embodied sensation displaces mental grappling, inviting the clarity of being in the moment, off balance. Multiple truths emerges from this multi-sensory experience. Sudden insights illuminate my being as cross-lateral connections forge new neural pathways, opening to possibilities.

It is within this embodied seeking that we process, strategize, release negativity, and build hope for the future. Through space, time, and physicality we come to know what we stand on and for. Dance is transformation; an invitation to engage with the world and ourselves as processes rather than objects. Unseen, we have the opportunity to get messy and honest with ourselves. We can practice facing our fears and confronting our shadows, so as to move through the world taking action, rather than being constantly manipulated by reaction. If our practice includes switching directions, staying grounded while reaching, and a continual curiosity dedicated to reframing limitations as creative prompts, we are able to face challenges like the present moment as potent opportunities to speak truth to power, and reimagine the next moves. 
In contrast, a Departmental Zoom meeting. I witness colleagues in threatened positions of power funneling immense amounts of energy into strategizing how to maintain historic standards in an idolization of, 'the way things have always been done.' New potentialities are discarded in attempts to, 'return to normal,' even while we all know, 'normal' was racist, homophobic, transphobic, misogynistic, ageist, and ableist, among other things.

Here and now is where our practice matters. Having taken the time to resource within the body, we are able to find the courage to dissent from the status quo and to advocate for change, because we know in our cells that change is the only constant. Moderating difficult conversations and effectively communicating across difference, we are grounded and emboldened by unseen embodied practices. Navigating each moment as dance research supports the disruption of attachments to familiar modes of assessment and assigning value. It gives us the courage to try new things, and to believe in life as continually unfolding potentiality. Our embodied advocacy for social justice, which we engage in as teachers, colleagues, artists, and citizens, is not a performance, not a show, but another site in which we dance, now.

\section{Biography}

Catherine Cabeen, MFA, RSMT is an artist and teacher based in NYC. She is a former dancer with the Bill T Jones/Arnie Zane Company, the Martha Graham Dance Company, and Richard Move's MoveOpolis!, among others. She directed Hyphen, an interdisciplinary performance group from 2009-2019. Cabeen is currently an Associate Professor of Dance at Marymount Manhattan College (MMC). Cabeen is also a certified yoga instructor and a teaching artist for the Bill T Jones/Arnie Zane Company.

\section{Email: ccabeen@mmm.edu}

Website: catherinecabeen.com 